\title{
Notas SOBRE A SOCIOLOGIA DA AÇÃo E A ÉTICA PROTESTANTE E O ESPÍRITO DO CAPITALISMO
}

\author{
Janine TARGINO*
}

RESUMO: A sociologia da ação, também chamada de sociologia interacionista ou acionista, refere-se a uma perspectiva que se afasta das definições que contemplam as atividades dos atores sociais e suas representações como meras manifestações do funcionamento do sistema. Dessa forma, vemos na sociologia da ação o comprometimento com a construção de um entendimento sobre as razões que levam os atores sociais a fazer o que fazem ou a acreditarem naquilo que acreditam. Devese sublinhar que o individualismo metodológico constitui o princípio fundamental da sociologia da ação. Neste artigo trataremos especificamente sobre como a sociologia da ação nos serve de norteadora para analisarmos a relação existente entre a ascese protestante e o desenvolvimento do capitalismo no Ocidente. Tal relação, tratada com bastante propriedade por Max Weber, nos revela que transformações ocorridas na esfera econômica podem encontrar estímulo em outros domínios sociais como, por exemplo, a religião.

PALAVRAS-CHAVE: Sociologia da ação. Ascese protestante. Capitalismo. Individualismo metodológico.

\section{A sociologia da ação}

Nascida na Alemanha, pelo menos em sua forma consciente e programática, a sociologia da ação ou sociologia interacionista constitui um dos paradigmas das ciências sociais. Seu princípio fundamental consiste na consideração de que

\footnotetext{
UENF - Universidade Estadual do Norte Fluminense Darcy Ribeiro. Centro de Ciências do Homem. Campos dos Goytacazes - RJ - Brasil. 28013602 - janine.targino.silva@gmail.com.
} 
todo e qualquer fenômeno social trata-se de um desdobramento de ações, atitudes, convicções e comportamentos individuais. O segundo princípio desta vertente sociológica indica que o sociólogo que pretende explicar um fenômeno social deve buscar o sentido dos comportamentos individuais que estão na sua origem (BOUDON, 1995).

O individualismo metodológico, princípio central da sociologia da ação, sublinha que para a elaboração satisfatória de uma explicação sobre um fenômeno social é necessário descobrir suas causas individuais, isto é, localizar as razões que levam os atores sociais a fazerem o que fazem ou a acreditarem plenamente naquilo que acreditam (BOUDON, 1995). Entendendo que todo fenômeno social é produto de ações, crenças ou comportamentos individuais, o individualismo metodológico sustenta a validade da explicação de fenômenos macroscópicos através de suas causas microscópicas.

Deve-se ter cuidado, aqui, em distinguir os diversos sentidos da palavra "individualismo", e em não confundir o sentido metodológico com o sentido moral ou o sentido sociológico. Individualista no sentido moral é aquele que faz do indivíduo a fonte suprema dos valores morais. Uma sociedade é individualista, no sentido sociológico, sempre que a autonomia do indivíduo é nela considerada um valor dominante. No sentido metodológico, a noção de individualismo tem um significado totalmente diverso: implica apenas que, para explicar um fenômeno social, é necessário descobrir suas causas individuais, ou seja, compreender as razões que levam os atores sociais a fazer o que fazem ou a acreditarem naquilo que acreditam. (BOUDON, 1995, p. 33)

Além de observar que um fenômeno social deve ser interpretado como efeito de ações, convicções e comportamentos individuais, a sociologia da ação também aponta que é preciso colocar em evidencia o porquê, ou melhor, o sentido dessas ações ou convicções. É assim que Weber irá falar em compreensão quando se refere a este momento da análise. Dessa forma, sob o prisma da sociologia da ação, explicar um fenômeno social implica a determinação dos comportamentos individuais de que ele é feito, assim como também alude à necessidade de que tais comportamentos identificados sejam compreendidos (BOUDON, 1995).

Da forma como é aplicada na sociologia de Max Weber, a noção de compreensão refere-se exclusivamente ao ator individual, pois entende que um momento essencial de qualquer análise sociológica consiste em reencontrar o sentido de seu comportamento (BOUDON, 1995). Por conseguinte, encontrar o sentido do comportamento dos atores, ou compreender esse comportamento, significa o mesmo que redescobrir as razões que levam os atores a fazerem o que fazem. No entanto, 
torna-se importante destacar que a metodologia individualista da sociologia da ação de forma alguma sugere uma visão atomista das sociedades, já que exige a consideração dos indivíduos enquanto atores inseridos em um contexto social. Igualmente, é válido sublinhar que a sociologia de Weber não está comprometida com a rejeição completa da elaboração de relações gerais ou de um saber nomológico sobre a sociedade (FREUND, 2006)

De fato, Weber apenas se recusa a limitar a Sociologia sob esse único aspecto, ao mesmo tempo em que demonstra interesse pelo estudo dos sentidos que os atores sociais atribuem às suas ações em sociedade (FREUND, 2006).

Sendo assim, a noção de compreensão presente na sociologia da ação sustenta que é possível, por meio da verificação de fatos, descobrir as razões do comportamento do ator social, isto é, pôr em evidência o sentido de uma atividade (FREUND, 2006). Ainda, sobre os princípios da sociologia da ação, pode-se dizer que:

O primeiro princípio fundamental da sociologia da ação consiste em levar a sério o fato de que todo fenômeno social, qualquer que seja, é sempre o resultado de ações, de atitudes, de convicções, e em geral de comportamentos individuais. $\mathrm{O}$ segundo princípio, que completa o primeiro, afirma que o sociólogo que pretende explicar um fenômeno social deve procurar o sentido dos comportamentos individuais que estão em sua origem. (BOUDON, 1995, p. 28)

Este panorama conceitual que esboçamos até aqui nos leva inevitavelmente ao conceito de ação social. Fundamental na sociologia weberiana, este conceito constitui um tipo ideal ${ }^{1}$ em essência, uma vez que o fenômeno ao qual a ação social se refere não pode ser encontrado de maneira cristalizada no âmbito da sociedade. Weber (2014) nos diz que a ação social pode ser determinada de modo racional referente a fins, de modo racional referente a valores, de modo afetivo e/ou de modo tradicional. A ação social racional referente a fins diz respeito ao indivíduo que "orienta sua ação pelos fins, meios e consequências secundárias, ponderando racionalmente tanto os meios em relação às consequências secundárias, assim como os diferentes fins possíveis entre si” (WEBER, 2014, p. 16). Por outro lado, a ação social racional referente a valores está fundamentada no ato planejado com referência às convicções do indivíduo que pratica a ação. A ação social afetiva trata de "sublimação, quando a ação afetivamente condicionada aparece como descarga consciente do estado emocional" (WEBER, 2014, p. 15), enquanto a ação social

Pode-se definir o conceito de tipo ideal da seguinte forma: "um conceito ideal é normalmente uma simplificação e generalização da realidade (...). Sob esse aspecto, a construção é simplesmente um recurso técnico que facilita uma disposição e terminologia mais lúcidas" (WEBER, apud QUINTANEIRO; BARBOSA; OLIVEIRA, 2002, p. 113). 
tradicional pode ser considerada como "uma reação surda a estímulos habituais que decorre na direção da atitude arraigada" (WEBER, 2014, p. 15).

Ainda, a definição weberiana para a ação social envolve outros elementos substanciais como, por exemplo, o fato de que nem todo tipo de ação é ação social e nem todo tipo de contato entre pessoas tem caráter social.

A ação social (incluindo omissão ou tolerância) orienta-se pelo comportamento de outros, seja este passado, presente ou esperado como futuro (vingança por ataques anteriores, defesa contra ataques presentes ou medidas de defesa para enfrentar ataques futuros) os "outros" podem ser indivíduos e conhecidos ou uma multiplicidade indeterminada de pessoas completamente desconhecidas. (WEBER, 2014, p. 14)

Tal como sublinha Cohn (1979) no livro Crítica e Resignação, Weber concentra sua análise sobre o sentido da ação social, uma vez que a unidade compreensível da ação é dada pelo seu sentido. Desta forma, Weber insiste no caráter subjetivo do sentido da ação e enfatiza que o único elemento empiricamente observável do sentido é o agente da ação.

Isto posto, podemos agora partir para a análise de alguns pontos de $A$ ética protestante e o espirito do capitalismo (WEBER, 2014). Nesta obra, ele faz uma exposição sobre as razões válidas para o comportamento singular dos calvinistas que, em função de suas crenças religiosas, buscavam êxito nos negócios e investiam seus lucros sem dissipá-los em luxo e ostentação. Expõe sua tese de que as ideias puritanas influenciaram singularmente o desenvolvimento do capitalismo, deixando claro que sua intenção é apontar uma das causas comprováveis para o desenvolvimento do capitalismo da maneira como o vimos no Ocidente. Ou seja, ao reconhecer que a relação existente entre o puritanismo e o capitalismo é uma entre várias outras relações que podem ter favorecido o desenvolvimento do capitalismo, Weber (2014) busca construir uma argumentação que se afasta da interpretação unilateral dos fatos.

\section{A ética protestante e o espírito do capitalismo}

Segundo Aron (2003), Weber dedicou-se a demonstrar que a conduta dos homens nas diversas sociedades somente pode ser compreendida dentro do quadro da concepção geral que esses homens possuem da própria existência. Seguindo essa perspectiva, os dogmas religiosos, assim como a interpretação dos mesmos, são partes integrantes da visão de mundo que os indivíduos têm. Dessa forma, é 
necessário entender tais perspectivas para que seja possível compreender a conduta dos indivíduos e dos grupos.

Além disso, de acordo com o ponto de vista de Weber, as concepções religiosas são capazes de atuar como fatores de orientação da conduta econômica e, justamente por isso, o autor considera tais concepções como forças que transformam a economia das sociedades. Assim, foi sobre estas duas considerações que ele construiu seu argumento sobre as relações entre o espírito do capitalismo e a ética protestante (ARON, 2003).

Em primeiro lugar, de acordo com Weber (2004), não há apenas um capitalismo, mas sim capitalismos. Segundo o autor, o capitalismo pode ser encontrado em vários lugares e épocas, mas apenas no Ocidente o capitalismo alcançou um grau extraordinário de racionalização no que diz respeito à forma como a produção e a atividade profissional passam a ser conduzidas. Referindo-se ao espírito do capitalismo ele nos diz que:

Se puder ser encontrado algo a que se possa aplicar esse termo, com algum significado compreensível, esse algo só poderá ser uma realidade histórica, isto é, um complexo de elementos associados na realidade histórica que nós aglutinamos em um todo conceitual, do ponto de vista de seu significado cultural.

Tal conceituação histórica, contudo, uma vez que seu conteúdo se refere a um fenômeno significativo por sua individualidade única, não pode ser definida pela fórmula genus proximum, differentia specifica, mas deve ser montada gradualmente a partir de suas partes individuais, tomadas da realidade histórica que a constitui. Por isso, o conceito final e definitivo não poderá ser encontrado no início, mas aparecerá no fim da investigação. (WEBER, 2004, p. 45)

Tendo em vista estas observações, o autor constrói um tipo ideal do capitalismo utilizando-se de uma definição centrada em certas características escolhidas em função dos interesses despertados pela pesquisa. A principal destas características seria a definição do capitalismo pela existência de empresas que possuem como objetivo central a produção do maior lucro possível através de uma organização racional do trabalho e da produção. É a coexistência do desejo pelo lucro e da disciplina racional aplicada ao trabalho, segundo Weber (2004), que constituem o traço singular do capitalismo ocidental e o diferencia dos demais. A auri sacra fames, ou busca desenfreada por lucro, existiu em todas as sociedades, mas no capitalismo ocidental este desejo de ganho irá ser satisfeito com o uso da disciplina, e não através da aventura e da especulação. Assim sendo: 


\section{Janine Targino}

A persecução do lucro, do dinheiro, da maior quantidade possível de dinheiro, não tem, em si mesmo, nada que ver com o capitalismo. Tal impulso existe e sempre existiu entre garçons, médicos, cocheiros, artistas, prostitutas, funcionários desonestos, soldados, nobres, cruzados, apostadores, mendigos etc. (...) A ganância ilimitada de ganho não se identifica nem de longe com o capitalismo, e menos ainda com seu "espírito". O capitalismo pode eventualmente se identificar com a restrição, ou pelo menos com uma moderação racional desse impulso irracional. O capitalismo, porém, identifica-se com a busca do lucro, do lucro sempre renovado por meio da empresa permanente, capitalista e racional. Pois assim deve ser: numa ordem completamente capitalista da sociedade, uma empresa individual que não tirasse vantagem das oportunidades de obter lucros estaria condenada à extinção.

Definamos agora nossos termos com uma precisão algo maior do que a usual. Definiremos como ação econômica capitalista aquela que repousa na expectativa de lucros pela utilização das oportunidades de troca, isto é, nas possibilidades (formalmente) pacíficas de lucro. Onde a aquisição capitalística é obtida racionalmente, a ação correspondente é ajustada por um cálculo em termos de capital. (WEBER, 2004, p. 26)

Diversas foram as pré-condições necessárias para que a configuração do capitalismo ocidental tal qual é observada por Weber se concretizasse. A possibilidade efetiva do cálculo de todos os custos, a previsibilidade racional das decisões jurídicas proporcionada pela atuação de um direito formal e a ordem estatal regida por uma lei racionalmente cognoscível fazem parte do conjunto de tais précondições (JASPERS, 1977).

No entanto, o fim da escravidão, o direito formal e a ordem estatal legal, condições que possuem em comum o traço da racionalização da existência, não foram suficientes para produzir o espírito da disposição capitalista eficiente para o trabalho (JASPERS, 1977). Da forma como é compreendida por Weber, a ideia de que o trabalho árduo é um dever que traz em si mesmo uma recompensa é uma característica do homem que vive no mundo industrial moderno. O homem deve trabalhar da melhor forma possível em sua ocupação remunerada não somente porque precisa fazê-lo, mas também porque possui desejo para se entregar a essa atividade, pois este é um sinal de virtude e de satisfação pessoal. Esta maneira de perceber o trabalho expressa o moderno espírito do capitalismo, com toda a sua despreocupação em relação a propósitos superiores de origem transcendental. Mas, em seu nascedouro, tal forma de observar o trabalho esteve especialmente baseada em um significado religioso, e foi para elucidar esta questão que Weber empregou seus esforços (BENDIX, 1986). 
Weber (2004) estabelece um contraste importante entre o espírito do capitalismo e a atividade econômica que designou como tradicionalismo. Quando os trabalhadores preferem trabalhar menos e ganhar mais, quando buscam o máximo de conforto e o mínimo de esforço durante as horas de trabalho e quando não se interessam ou se mostram incapazes de adaptar-se a novos métodos de trabalho, vê-se manifesta atitudes tradicionalistas. Da mesma forma, quando os empresários optam por bens de qualidades variadas e não por uma produção padronizada, quando trabalham em um ritmo moderado, quando se mostram satisfeitos com rendas que permitam uma vida confortável e quando as relações com seus trabalhadores, clientes e competidores são diretas e essencialmente pessoais, também aí se pode perceber o tradicionalismo. Por outro lado, a avareza e o ímpeto ganancioso sem escrúpulos também são atitudes que diferem absolutamente do espírito do capitalismo (WEBER, 2004). Portanto, nem a adesão ao tradicionalismo, nem a avareza e a ganância inescrupulosa são compatíveis com a visão do trabalho árduo como uma virtude, isto é, como uma obrigação moral.

Seguindo as orientações de Weber (2004), temos que o trabalho visto sob o prisma da ideia de vocação tem origem religiosa. De acordo como o autor, a ideia de vocação provém de Lutero, mas a sua plena formação vem do calvinismo. A doutrina religiosa do calvinismo sustentava que o homem que deseja servir a Deus não deve aderir a uma ascese que o retira do mundo, mas sim deve servir a Deus em uma espécie de ascese intramundana. O homem, segundo o calvinismo, deve trabalhar para os outros e para que a vontade divina se concretize no mundo através da produção de boas obras. O trabalho, sob a ótica calvinista, não constitui um meio para extrair prazer do lucro e do sucesso.

O ponto chave para entendermos esta maneira singular do calvinista se comportar em relação ao trabalho é o dogma da predestinação. Para o calvinismo, Deus predeterminou todos os homens, ou seja, a escolha dos eleitos é feita previamente, sem a influência de qualquer ação dos homens. Ser ou não ser salvo é uma condição imposta pelos desígnios de Deus, e nada pode alterar isso. Desencantando o mundo ${ }^{2}$ ao extremo, o calvinismo irá indicar que:

No tocante à coisa mais importante da vida para o homem do tempo da reforma a sua salvação eterna - era ele forçado a seguir sozinho o seu caminho para encontrar um destino que já fora determinado para ele e para a eternidade. Ninguém poderia ajudá-lo. Nenhum padre, já que quem era escolhido só poderia entender a palavra de Deus em seu próprio coração.

\footnotetext{
2 Esta expressão faz referência ao conceito de desencantamento do mundo cunhado por Weber. Tal conceito diz respeito, como nos indica Pierucci, ao processo de racionalização no campo religioso e à eliminação da magia como meio de salvação (PIERUCCI, 2003).
} 


\section{Janine Targino}

(Para o calvinismo) nenhum sacramento, apesar dos sacramentos terem sido instituídos por Deus para o aumento de Sua glória, devendo por isso ser escrupulosamente observados, não eram meios para se obter a graça, mas apenas a externa subsidia subjetiva da fé. Nenhuma Igreja, embora se tivesse como certo que extra ecclesiam nulla salus, no sentido de que quem se mantivesse afastado da verdadeira Igreja nunca se poderia integrar ao grupo dos escolhidos por Deus; entretanto, a Igreja incluía entre seus membros os condenados. Estes poderiam fazer parte daquela e se submeter à sua disciplina, não para obter a salvação, que seria impossível, mas porque, pela glória de Deus, eles também deveriam ser forçados a obedecer a Seus mandamentos. E finalmente, nenhum Deus. Mesmo Cristo havia morrido apenas para os eleitos, para cujo benefício Deus decretara Seu eterno martírio. (WEBER, 2004, p. 82)

No entanto, mesmo que não haja nenhuma via possível para a conquista da graça, o puritano pode procurar sinais que indiquem sua posse ou não da salvação dada de antemão por Deus. Através de uma vida pessoal submetida aos mandamentos divinos e do êxito obtido por meio de sua ação no mundo, isto é, por meio de sua atividade profissional, o indivíduo pode encontrar uma resposta para a dúvida angustiante sobre ser ou não um eleito. $\mathrm{O}$ trabalho, quanto mais eficaz, é percebido como a manifestação da glória de Deus e um indicador da salvação. O êxito no trabalho ratifica a vocação pessoal e, ao mesmo tempo, também pode ser interpretado como uma indicação da eleição. E é justamente por isso que os indivíduos imbuídos pela crença no dogma da predestinação se entregam incansavelmente ao trabalho não como uma forma de obter lucro ou para usufruir prazeres mundanos, mas sim para buscar um sinal de que realmente possuem o estado de graça. Usufruir os prazeres do mundo por meio do uso daquilo que é ganho com o trabalho seria uma prova de não eleição, uma vez que cada homem é responsável por aquilo que lhe é posto em suas mãos.

A incerteza sobre o estado de graça permeia a vida do homem que orienta a sua existência de acordo com esses preceitos. Ainda que alcance grande êxito com seu trabalho, ou seja, com sua ação no mundo, a dúvida perene referente à posse do estado de graça motiva o homem a buscar incessantemente sempre mais êxito em sua atividade. Segundo Weber (2004), fora esta concepção religiosa aderida por muitos que transformou o trabalho em uma atividade fundamentada em cálculos racionais.

A busca pelo êxito no trabalho contribuiu para o fortalecimento do rigor da conduta pessoal. A conduta essencialmente ascética do puritanismo foi uma das responsáveis pela formulação racional de toda existência, de acordo com a vontade de Deus. O puritano, através da disciplina que empregava em sua atividade profissional, exercia um constante domínio de si mesmo, e isso teve 
como consequência a profunda racionalização do comportamento individual. Diferentemente do catolicismo, que expressava um domínio mais frouxo sobre as atividades dos homens, a atitude puritana sugeria uma regulamentação rígida das atividades exercidas no mundo. Dessa maneira, o puritano mostrou-se apto para a tarefa de organização das empresas, assim como também para a racionalização da economia.

Embora o êxito profissional tenha como desdobramento inerente o acúmulo de riqueza, o puritanismo não via aí nenhuma espécie de contradição. A acumulação de riquezas em si não era reprovável, apesar de somente ser permitido tirar do que foi adquirido o suficiente para uma vida digna, sem nenhum tipo de ostentação. Tendo a vida ativa como uma legítima forma de devoção, o absolutamente condenável pelo puritanismo era o repouso na posse, que levava inevitavelmente ao desperdício de tempo e à queda nas tentações da carne. Tendo em vista que o trabalho consistia em uma forma de glorificar a Deus, a perda de tempo na ociosidade ou no usufruto das riquezas eram atitudes abomináveis, já que a produtividade sempre maior no trabalho deveria ser uma meta permanente na vida do puritano.

Além da ostentação, o puritano também deveria se afastar das distrações da música e do teatro, e de qualquer forma de satisfação dos sentidos na arte, salvo quando tal satisfação não implicasse gastos. Os excessos emocionais na vida pessoal também deveriam ser evitados, uma vez que relacionamentos desta ordem poderiam envolver o perigo da idolatria. O homem não deveria confiar totalmente em seus semelhantes, já que qualquer um poderia ser um não eleito e apenas Deus era digno de confiança. A vida do puritano não somente era permeada por uma constante preocupação em função da busca incessante pelos sinais de sua eleição, mas também por um profundo sentimento de solidão.

A junção entre uma grande produtividade no trabalho e o afastamento em relação a uma vida de luxo e ostentação foi, segundo Weber (2004), a responsável pela criação de um estilo de vida que esteve diretamente ligado ao espírito do capitalismo, propiciando o seu desenvolvimento. Em seu esforço para conferir ao trabalho o caráter de manifestação da glória de Deus, o puritano entedia que era extremamente necessário empregar o lucro sob forma de investimentos para aprimorar os resultados de seu trabalho. Como desdobramento principal desse comportamento houve um grande acumulo de capital, e fora exatamente esse um dos elementos fundamentais para a constituição do espírito do capitalismo, baseado em uma conduta e organização racionais dos negócios.

Há, nos diz Weber (2004), uma afinidade eletiva ${ }^{3}$ entre a atitude protestante e a atitude capitalista. Por um lado, o capitalismo implica o estabelecimento de uma

\footnotetext{
3 Segundo Kalberg (2010, p. 131), o conceito de afinidade eletiva encontrado na sociologia weberiana é um "conceito inspirado em Goethe, e supõe a existência de uma conexão 'interna' entre dois fenômenos
} 
organização racional do trabalho e investimento da maior parte do lucro obtido nos meios de produção. Por outro, a ética protestante oferece uma explicação e uma justificativa, ou melhor, um sentido, para a busca do lucro não para o usufruto do mesmo, mas sim para investir em meios de produção e assim produzir cada vez mais e mais.

Contudo, em sua exposição sobre o vínculo entre a ética protestante e o espírito do capitalismo, Weber (2004) deixa claro que sua intenção não é pôr em evidência a causa do capitalismo, mas sim uma das causas comprováveis para do mesmo. Ele apenas busca destacar, através do uso de meios da pesquisa empírica e de interpretação compreensiva, as condições e um dos fatores positivos que atuaram para a formação do espírito do capitalismo no Ocidente.

Em primeiro lugar, é importante acentuar que Weber está longe de afirmar que o protestantismo foi a "única" causa do capitalismo. Além de assinalar que o problema da origem do capitalismo admite causas múltiplas e complexas (econômicas, políticas, militares, técnicas, jurídicas, etc.), não se pode sustentar que a religião (ou a ética) seria propriamente o fator de origem do comportamento econômico capitalista, num sentido linear e determinista. Esse ponto é da maior importância: Weber não trata, de maneira nenhuma, da origem do capitalismo como "sistema econômico", mas apenas da origem da conduta ou disposição capitalista como uma determinada forma de "ação social". (SELL, 2015, p. 125)

Bendix (1986) explica que embora nenhum dos grandes reformadores tivesse a pretensão de contribuir para o desenvolvimento do espírito do capitalismo, Weber demonstra que as doutrinas por eles sustentadas caminharam para este sentido. Dentre as doutrinas que insurgem no momento da Reforma Protestante, o autor sublinha a importância do calvinismo neste fenômeno. Fora a doutrina calvinista da predestinação, de acordo com a qual a salvação de um indivíduo era determinada por uma decisão previamente tomada por Deus, que ofereceu um sentido transcendental ao êxito no trabalho, assim como também impulsionou a adoção de um comportamento racional na atividade profissional. Dessa forma, a ética protestante fora apenas um dentre diversos elementos que apontavam na direção de um maior racionalismo em toda a vida social, além de criar determinadas motivações que favoreceram a formação do regime capitalista. Assim, no Ocidente o racionalismo foi marcado por um desenvolvimento múltiplo peculiar e ligado de maneira mais ou menos direta aos desdobramentos do desenvolvimento do capitalismo.

diferentes que têm raízes em um aspecto comum e/ou uma clara ligação histórica". 
No momento em que publica sua obra $A$ ética protestante e o espírito do capitalismo ${ }^{4}$, Weber (2014) nos diz que a motivação metafísica ou moral que moveu os indivíduos para uma conformação à lei do capitalismo já havia se dissolvido. Por conseguinte, o sistema capitalista estaria plenamente estabelecido. Todavia, este novo panorama não atribui descrédito à análise weberiana sobre a formação do espírito do capitalismo. Mesmo que não esteja mais fundado sobre as motivações psicorreligiosas que atuaram em sua origem, o espírito do capitalismo é amplamente devedor de tais motivações.

O puritano quis trabalhar no âmbito da vocação; e fomos todos forçados a segui-lo. Pois quando o ascetismo foi levado para fora das celas monásticas, se fez introduzir na vida cotidiana e começou a dominar a moralidade laica, fêlo contribuindo poderosamente para a formação da moderna ordem econômica. Essa ordem está hoje ligada às condições técnica e econômica da produção pelas máquinas, que determina com força irresistível a vida de todos os indivíduos nascidos sob este regime, e não apenas os envolvidos diretamente na aquisição econômica. E talvez assim determine até que seja queimada a última tonelada de carvão fóssil. Na visão de Baxter, o cuidado para com os bens materiais deveria repousar sobre os "ombros do santo como um leve manto, que pode ser atirado de lado a qualquer momento". Mas o destino quis que o manto se tornasse uma prisão de ferro. (WEBER, 2004, p. 135)

\section{Conclusão}

Diante de tudo que fora exposto até aqui, pode-se dizer que os ensinamentos puritanos conferiram às atividades econômicas um ethos baseado no planejamento e no autocontrole, e assim encorajaram o êxito terreno influenciando o estilo de vida ascético. Foi dessa forma que o ascetismo protestante rompeu com a moral da proibição tradicional contra o desejo de aquisição e lucro e contribuiu para a formação do espírito do capitalismo. Em síntese, é correto afirmar que:

O núcleo da teoria de Weber é que as atitudes envolvidas no espírito do capitalismo derivavam da religião. O cristianismo, em geral, teve o papel de promover essa perspectiva, mas a força motivadora essencial foi proporcionada pelo impacto do protestantismo, em particular: o puritanismo. Os primeiros capitalistas eram principalmente puritanos, e muitos aderiram aos pontos de vista calvinistas. Weber argumentava que certas doutrinas eram a fonte direta do espírito do capitalismo.

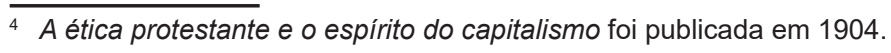




\section{Janine Targino}

Uma delas era a ideia de que os seres humanos são instrumentos de Deus na Terra, chamados pelo Todo-Poderoso para trabalhar em uma vocação - uma ocupação para a glória maior de Deus.

Um segundo aspecto importante do calvinismo era a noção de predestinação, segundo a qual apenas certos indivíduos predestinados estão entre os "eleitos" para entrar no paraíso, na vida eterna. Na doutrina original de Calvino, nada que uma pessoa faça na Terra pode mudar se ela é um dos eleitos; isso já foi predeterminado por Deus. Todavia, essa crença causava tanta ansiedade entre seus seguidores que foi modificada, permitindo que os crentes reconhecessem certos sinais de elegibilidade.

O sucesso no trabalho em uma determinada vocação indicado pela prosperidade material, tornou-se o principal sinal de que uma pessoa era verdadeiramente um dos eleitos. (GIDDENS, 2012, p. 72)

Em sua análise, Weber (2004) busca elucidar os vínculos existentes entre a conformação intelectual ou espiritual da ética protestante (com ênfase sobre o calvinismo) e o espírito do capitalismo. Ele se afasta da questão da causalidade que envolve o surgimento e desenvolvimento do capitalismo, e esforços fluem no sentido de relacionar de modo compreensivo uma maneira de agir no mundo com um pensamento religioso. O problema sociológico a ser analisado em $A$ ética protestante e o espírito do capitalismo (WEBER, 2004) é o da influência das concepções de mundo nas organizações sociais e nas atitudes individuais.

Sem pretender que a sua compreensão dos fatos fosse a única possível, Weber quis apreender a atitude global de indivíduos e grupos, pois a observação global dos fatos era de suma importância para o autor. Ao expor as motivações que impulsionaram os puritanos a adotarem um tipo de comportamento singular, ele mostra que existem organizações inteligíveis do pensamento e da existência que, mesmo não sendo científicas, não são destituídas de sentido (ARON, 2002). É assim que Weber tende

[...] a reconstruir estas lógicas, mais psicológicas do que científicas, pelas quais se passa, por exemplo, da incerteza sobre a salvação para a procura de sinais de eleição. Trata-se de uma passagem inteligível, sem que, no entanto, se ajuste propriamente às regras do pensamento lógico-experimental. (ARON, 2002, p. 788)

Tendo em mente as considerações apresentadas anteriormente, vemos que A ética protestante e o espírito do capitalismo (WEBER, 2004) é uma obra que 
incorpora os elementos da sociologia da ação. A consideração de que todo e qualquer fenômeno social consiste em um desdobramento de ações, atitudes, convicções e comportamentos individuais, e o destaque dado à necessidade de evidenciar $\mathrm{o}$ porquê, ou melhor, o sentido dessas ações ou convicções, é princípio basilar da sociologia da ação e está presente em toda a análise realizada por Weber. São os indivíduos agindo cotidianamente e racionalizando sobremaneira as suas ações que constituem o centro do estudo feito pelo autor. É através da observação das motivações que movem esses indivíduos que o autor busca compreender o sentido de comportamentos individuais que estão fortemente ligados à origem do espírito do capitalismo. Partindo deste ponto, ele assinala os elementos sobre os quais constrói o seu argumento de que há uma afinidade eletiva entre a ética protestante e o espírito do capitalismo. O relevante para Weber (2004) era a ação dos homens, e a sociedade capitalista é vista como fruto desta ação.

\title{
Remarks On The Sociology Of Action, The Protestant Ethic And The SpIRIt Of Capitalism
}

\begin{abstract}
The sociology of action, also called interactionist or shareholder sociology, is a perspective that departs from definitions that consider the activities of social actors and their representations as mere manifestations of the workings of the system. Consequently, we see in the sociology of action a commitment to build an understanding of the reasons that lead social actors to do what they do or to believe in what they believe. It should be emphasized that methodological individualism constitutes the fundamental principle of the sociology of action. In this article we will deal specifically with how the sociology of action serves as a guide to analyze the relationship between Protestant asceticism and the development of capitalism in the West. Such a relationship, treated fairly well by Max Weber, reveals to us that transformations in the economic sphere can find stimulus in other social domains, such as religion.
\end{abstract}

KEYWORDS: Sociology of action. Protestant Ascesis. Capitalism. Methodological individualism.

\section{REFERÊNCIAS}

ARON, Raymond. As Etapas do Pensamento Sociológico. São Paulo: Martins Fontes, 2002 . 
BENDIX, Reinhard. Max Weber, um perfil intelectual. Brasília: Editora Universidade de Brasília, 1986.

BOUDON, Raymond. Ação. In: BOUDON, Raymond (org). Tratado de Sociologia. Rio de Janeiro: Jorge Zahar Editor, 1995.

COHN, Gabriel. Crítica e Resignação: Fundamentos da Sociologia de Max Weber. São Paulo: T. A. Queiroz, 1979.

FREUND, Julien. Sociologia de Max Weber. Rio de Janeiro: Forense Universitária, 2006. GIDDENS, Anthony. Sociologia. Porto Alegre: Penso, 2012.

JASPERS, Karl. Método e visão do mundo em Weber. In: COHN, Gabriel (org). Sociologia: para ler os clássicos. Rio de Janeiro: LTC, 1977.

KALBERG, Stephen. Max Weber: uma introdução. Rio de Janeiro: Zahar, 2010.

PIERUCCI, Antônio Flávio. O Desencantamento do mundo: todos os passos do conceito em Max Weber. São Paulo: Editora 34, 2003.

QUINTANEIRO, Tania; BARBOSA, Maria Ligia de Oliveira; OLIVEIRA, Márcia Gardênia de. Um toque de clássicos: Marx, Durkheim e Weber. 2. ed., rev. e ampl. Belo Horizonte: UFMG, 2002.

SELL, Carlos Eduardo. Sociologia clássica: Marx, Durkheim e Weber. Petrópolis: Vozes, 2015.

WEBER, Max. Economia e sociedade. Brasília: Editora UNB, 2014.

2004.

. A ética protestante e o espírito do capitalismo. São Paulo: Editora Martin Claret,

Recebido em 10/02/2017.

Aprovado em 20/06/2017. 